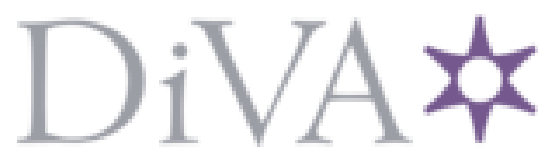

http://www.diva-portal.org

\title{
Postprint
}

This is the accepted version of a paper published in European journal of internal medicine. This paper has been peer-reviewed but does not include the final publisher proof-corrections or journal pagination.

Citation for the original published paper (version of record):

Vasaitis, L. (2016)

IgG4-related disease: A relatively new concept for clinicians.

European journal of internal medicine, 27: 1-9

http://dx.doi.org/10.1016/j.ejim.2015.09.022

Access to the published version may require subscription.

N.B. When citing this work, cite the original published paper.

Permanent link to this version:

http://urn.kb.se/resolve?urn=urn:nbn:se:uu:diva-264947 
Review Article

IgG4-related disease: A relatively new concept for clinicians

\section{Lilian Vasaitis}

Section of Rheumatology, Department of Medical Sciences, Uppsala University, Uppsala, Sweden

Corresponding author:

Lilian Vasaitis, MD, Rheumatology Clinic, Entrance 30, Uppsala University Hospital, SE-751 85 Uppsala, Sweden.

Phone: +46-18-6114486; fax +46-18-5558432.

E-mail address: lilian.vasaitis@medsci.uu.se

Keywords: IgG4-related disease; IgG4 immunoglobulin; Diagnosis; Treatment 


\begin{abstract}
IgG4-related disease (IgG4-RD) is a recently recognized chronic fibrotic inflammation, which can affect almost every organ, and may come to clinical attention first due to visible organ swelling or organ dysfunction, or is identified incidentally by imaging and specific biopsy. The disorder has an allergic background and is immune-mediated. Up-regulated responses of $\mathrm{T}$ helper 2 and $\mathrm{T}$ regulatory cells and their cytokines play a major role in disease progression. About $30-50 \%$ of patients are atopic or have mild eosinophilia. IgG4-RD predominantly affects middle-aged male patients. The cornerstones of diagnosis of the disease are compatible clinical features and typical histopathology. Swelling of salivary and lacrimal glands, lymphadenopathy, and type 1 autoimmune pancreatitis (AIP) are the most common manifestations of the disease. However, other tissues and organs, such as retroperitoneum, lung, kidney, aorta, upper airways, thyroid gland, meninges, heart, mesenterium and skin may be involved. Typical histopathology is lymphoplasmacytic infiltration abundant in IgG4positive plasma cells, storiform-type fibrosis, and obliterative phlebitis. Elevated serum IgG4 concentration supports the diagnosis. Characteristic imaging features such as a "capsule-like rim" surrounding the pancreatic lesions is highly specific to type 1 AIP. 18Ffluorodeoxyglucose positron emission tomography/computed tomography enables mapping the sites of inflammation, permits evaluation of the extent of the disease, helps in guiding biopsy decision, and may be used in monitoring response to treatment. Glucocorticoids alone or in combination with B-cell depletion with rituximab induces prompt clinical response to IgG4-RD.

This article reviews the current understanding, different clinical manifestations, and approaches to diagnosis and treatment of IgG4-RD.
\end{abstract}




\section{Highlights}

IgG4-related disease is a chronic fibrotic inflammation.

The disease affects multiple organs, is progressive, and impairs function.

The disorder has an allergic background and is immune-mediated.

Compatible clinical signs and typical pathology are the basis for the diagnosis.

Glucocorticoids and/or B-cell depletion induces prompt clinical response.

Immunoglobulin G4-related disease (IgG4-RD) is a chronic fibrotic inflammation, characterized by tissue infiltration by lymphocytes, IgG4-positive plasma cells, simultaneous development of fibrosis, and often, but not always, elevated serum levels of $\operatorname{IgG} 4(1,2)$. The disease can affect multiple organs. Early diagnosis of IgG4-RD is not easy because of the indolent course of the disease with vague, nonspecific symptoms. It may first come to clinical attention as visible organ swelling or detected organ dysfunction due to fibrosis, or is identified incidentally by imaging and specific biopsy when the patient undergoes investigation of suspected tumor disease. Most forms of organ involvement in IgG4-RD, even in the advanced fibrotic stages, respond well to glucocorticoids $(3,4)$. 
A comprehensive search for all articles in English until June 2015, with particular attention to articles published during the last ten years, with pertinent keywords IgG4-related disease, IgG4-RD and IgG4 was conducted using PubMed.

\section{Pathogenesis of IgG4-related disease}

It has been suggested that the disorder has an allergic background and is immune-mediated, where abnormal immune responses are observed. The responsiveness to immunosuppressive therapy supports an autoimmune or other chronic inflammatory etiology. About $30-50 \%$ of patients have a history of allergies, eosinophilia and/or elevated serum $\operatorname{IgE}$ levels $(5,6)$. In contrast to patients with autoimmune diseases supported by T helper 1 (Th1) or Th17mediated immunity and production of inflammatory cytokines interleukin-2 (IL-2), interferon gamma, and tumor necrosis factor alpha, the patients with IgG4-RD have mainly up-regulated

responses of Th2 (cytokines IL-4, IL-5, IL-13, and IL-21) and regulatory T (Treg) cells (IL-10 and transforming growth factor beta 1 (TGF- $\beta 1))(7)$.

Th2 induces an allergic immune response with eosinophilia and increased serum $\operatorname{IgE}(8,9)$. Activated mast cells, strongly positive for IgE, promote the differentiation of naïve T cells to Treg cells (10). IL-10 also known as anti-inflammatory cytokine promotes the differentiation of B cells to plasma cells and subsequent production of IgG4. IL-4 activates macrophages to produce high levels of IL-10. IL-21 produced by Th2 and T follicular helper cells, is important in the formation of germinal centers and stimulates production of IgG4 and infiltration of IgG4-positive plasma cells in affected tissues $(8,11,12)$. Inflammatory monocytes also play an important role in the formation of ectopic lymphoid follicles in IgG4RD (13). Massive infiltration by inflammatory cells with the formation of lymphoid follicles leads to enlargement of the affected organs and results in their dysfunction. Plasma cell expansion leads to hypergammaglobulinemia.

Antigen-induced circulating plasma cells in the blood have the phenotype 
$\mathrm{CD} 38^{\text {high }} \mathrm{DC} 27^{\text {high }} \mathrm{CD} 19^{+} \mathrm{CD} 20^{-} \mathrm{CD} 22^{-}$(short-lived plasmablasts) (14). A recent study showed that IgG4-RD is associated with elevated short-lived plasmablast counts in the blood, even in a subset of patients with normal serum IgG4 concentrations. Plasmablast count is superior to serum IgG4 concentrations as a biomarker for the diagnosis of IgG4-RD (15) and can be useful for monitoring disease activity and predicting relapse (16). The effect of rituximab, a chimeric monoclonal antibody against $\mathrm{CD} 20^{+} \mathrm{B}$ cells, may rely on depletion of $\mathrm{CD} 20^{+} \mathrm{B}$ lymphocytes, which are precursors to plasma cells. Short-lived plasma cells undergo apoptosis and IgG4 levels decline in the blood $(17,18)$. Long-lived memory plasma cells survive B-cell depletion. Long-lived plasma cells, Th2 memory cells, and expanding mutated plasmablasts may play a role in chronic and relapsing disease $(16,19)$.

Treg cells produce TGF $\beta-1$, which activates fibroblasts (20) and causes differentiation of endothelial/epithelial cells into myofibroblasts (21), resulting into tissue fibrosis development. Complex network of multiple pathways may be involved in the fibrosis pathogenesis (21).

\section{IgG4 immunoglobulin}

IgG4 is the least common of the four subclasses of $\operatorname{IgG}$ and accounts for $3-6 \%$ of total $\mathrm{IgG}$ in normal serum. IgG4 exhibits negligible binding to Fc $\gamma \mathrm{II}$ and Fc $\gamma \mathrm{III}$ receptors and $\mathrm{C} 1 \mathrm{q}$ protein complex, and is unable to activate the classical complement pathway. Although the IgG1 response is considered to precede the IgG4 response, the switch is driven by the repeated and prolonged exposure to the antigen (22).

Structural differences of the core IgG4 hinge allow the heavy chains to separate and recombine randomly forming antibodies with two different antigen-binding sites. The bispecific IgG4 molecules are unable to crosslink antigen and lose the ability to form immune complexes. In addition, IgG4 can bind the Fc portion of other IgG antibodies and may contribute to the molecule's anti-inflammatory effect $(23,24)$. Moreover, IgG4 may function 
as a blocking or neutralizing antibody, protecting the body from severe allergic reactions in response to food or environmental allergens $(22,25)$.

It is thus far not known whether IgG4 antibodies are pathogenic in IgG4-RD or are byproducts of the immune response, and no putative target antigen has been identified.

\section{History}

In 1892, Mikulicz described a patient with symmetrical and painless swelling of the lacrimal, parotid, and submandibular glands, so-called Mikulicz's disease (MD). Until recently, MD has been considered to be a subtype of Sjögren's syndrome (SS) in western countries, as a result of clinical and histopathological similarities (26). However, many differences between MD and SS have been reported in Japan. MD usually presents with bilateral and persistent swelling in at least two sites of the lacrimal and salivary glands, with higher frequency of males represented. Lymphoplasmacytic infiltration with lymphoid follicle formation causes swollen glands, but duct destruction is uncommon in MD. Serology is usually negative for anti-SS-A/SS-B antibodies, and in contrast to SS, dryness symptoms improve within days of starting glucocorticoids in MD patients (27).

In 1961, a case of chronic pancreatitis with hypergammaglobulinemia was reported (28). Autoimmunity was presumed as part of the mechanism in the development of the type 1 autoimmune pancreatitis (AIP) in 1995 (29), and in 2001, the association of this type of pancreatitis was reported with elevated serum concentrations of IgG4 (30). Moreover, in the following year, it was reported that IgG4-positive plasma cells prominently infiltrated pancreatic lesions (31). Various other organ dysfunctions have been found to be associated with MD and type 1 AIP, and the extrapancreatic infiltration by IgG4-positive plasma cells suggested a systemic nature of the inflammatory disease (32). After an international symposium in 2011, recommendations regarding the nomenclature for IgG4-RD (33) and consensus on the pathology of the disease (34) were established. 


\section{Epidemiology}

The epidemiology of the IgG4-RD remains poorly understood due to its recent recognition and the lack of larger epidemiological studies. In Japan, the estimated prevalence of type 1 AIP is 0.8 cases per 100,000 persons and the estimated incidence of $0.28-1.08 / 100,000$, with 336-1300 patients newly diagnosed per year and approximately 6,700-26,000 patients who developed the IgG4-RD over the last 20 years (35). Another study in Japan estimated the prevalence of approximately 6 individuals with IgG4-RD per 100,000 inhabitants (36). The IgG4-RD predominantly affects male patients, with the possible exception of those with principally head and neck involvement, in whom the gender distribution is almost equal (37). The average age at onset of symptoms is $50-60$ years, $(37,38)$ but some patients can show symptoms at a younger age, and the disease can even affect children (39-41).

\section{Diagnosis}

\subsection{Clinical symptoms}

Umehara et al. have proposed comprehensive clinical diagnostic criteria for IgG4-RD for practical use by nonspecialists (42). Organ-specific criteria have also been suggested for specialists $(43,44)$. The diagnosis of IgG4-RD should be made by the integration of clinical features, laboratory findings, typical histopathology, and radiology data (Fig 1).

One third of patients have a history of atopic disease including bronchial asthma, allergic rhinitis, nasal polyps, and atopic dermatitis, and non-atopic patients can exhibit peripheral blood eosinophilia and/or elevated IgE (5). A higher frequency of allergies (57\%) has been observed in a Chinese cohort study (6). 
Figure 1. Diagnostic work-up of IgG4-related disease, based on Umehara et al. proposed diagnostic criteria ${ }^{42}$

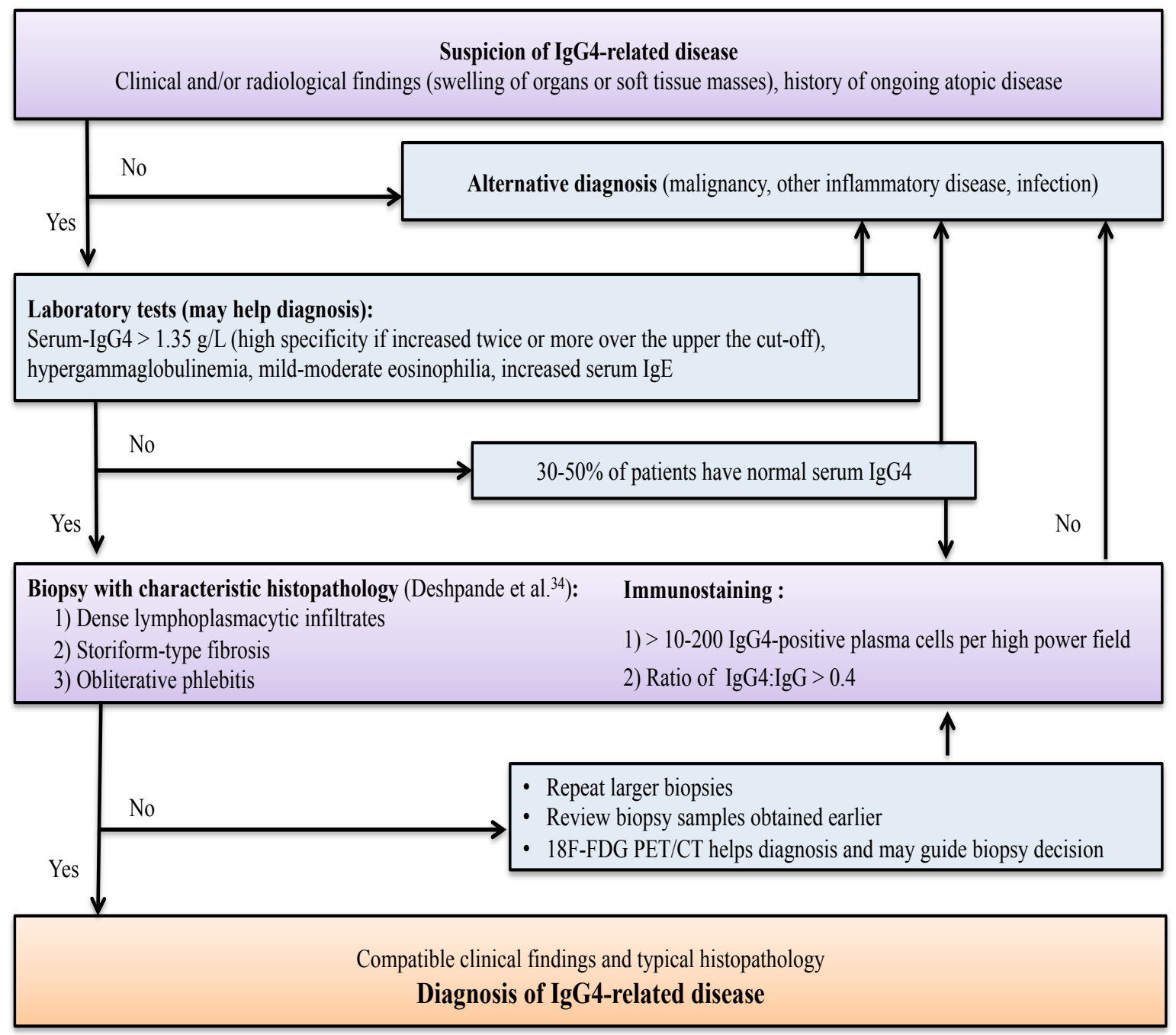

The clinical symptoms of IgG4-RD are wide-ranging, manifesting in one or more organs synchronously or metachronously. It may have a subacute or chronic course, marked by a spectrum of mild localized symptoms to major tissue damage and organ failure. Concurrent lymphadenopathy in the region of, or distant from, the extranodal sclerosing lesion can occur. Moreover, patients with IgG4-RD usually do not have constitutional symptoms such as fever, malaise, night sweats, or weight loss (45). Malignancies were reported in $7.4 \%$ of the patients with IgG4-RD (37). Extranodal marginal zone B-cell lymphoma may occur in ocular adnexa, salivary glands, or meningeal dura up to 5 years after diagnosis of IgG4-RD (46-48). 


\subsection{Laboratory tests}

Hematological tests are chiefly normal, sometimes with slightly elevated C-reactive protein, elevated ESR, anemia, thrombocytosis, and mild peripheral eosinophilia. However, serology may reveal elevated $\operatorname{IgE}(5,6)$, polyclonal hypergammaglobulinemia (37), hypocomplementemia ( $21 \%$ of cases, particularly with renal involvement), presence of antinuclear antibodies (16-50\%), and rheumatoid factor $(20 \%)(49,50)$. Elevated serum IgG4 can help make a diagnosis. IgG4 $>1.35 \mathrm{~g} / \mathrm{L}$ in serum, accepted as a cut-off value, demonstrated a sensitivity of $97.0 \%$ and a specificity of $79.6 \%$ in diagnosing IgG4-RD (51). However, some patients with early and/or limited stage of IgG4-RD do not present with high IgG4-globulinemia (51). Moreover, a study recently reported multiple non-IgG4-RD conditions, associated with elevated serum IgG4, leading to poor specificity $(60 \%)$ and low positive predictive value (34\%) of the test (52). In addition, increased serum IgG4 can be nonspecific, being elevated in 5\% healthy individuals, and can be associated with recurrent infections, autoimmune diseases, allergic conditions, carcinoma, cystic fibrosis with concomitant Pseudomonas aeruginosa, Castleman's disease, and IgG4-myeloma (52-55). About $30-50 \%$ of patients have normal serum IgG4 concentrations even in the presence of classic histopathology $(38,52)$. The prozone phenomenon, known to occur with some nephelometry assays in the setting of high antigen excess, may lead to major underestimations of IgG4 concentrations, and can be avoided by diluting the samples (56). In some cases, the increased serum IgG4 concentrations can also have shortcomings as predictors of disease flares (3). Increased plasmablast counts in the blood may serve as a biomarker of the disease (15) and can be useful for monitoring of the disease activity and predicting relapse $(16,38)$.

\subsection{Imaging}

Imaging features can show characteristic features in some organs, such as a "capsule-like rim" in type 1 AIP (57) and renal disease (58), radiologic abnormalities in IgG4-related lung 
disease (59) and periaortitis (60). A diffuse or focal pseudotumoral swelling of organs or soft tissue masses adjacent to abdominal or thoracic organs appear with soft tissue attenuation and well-defined margins on precontrast computed tomography (CT), and are iso- to hypointense on T2-weighted magnetic resonance imaging (MRI), with homogeneous enhancement, reflecting increased cellularity and fibrosis. The adjacent bone can show remodeling with erosion or sclerosis (61).

Imaging with 18F-fluorodeoxyglucose positron emission tomography/computed tomography (18F -FDG PET/CT) enables mapping of the sites of inflammation by highlighting hypermetabolic activity, permits evaluation of the extent of the disease, and helps in guiding biopsy decision and in monitoring response to treatment (62). Other organ involvement has been detected at diagnosis of IgG4-related glandular disease in $>60 \%$ of cases when using 18F-FDG PET/CT scan (37). However, imaging features and the abnormal uptake on 18FFDG PET/CT scans do not permit reliable distinction between IgG4-RD, inflammation of other causes, and cancer (63).

\subsection{Histopathology}

The current gold standard for diagnosing IgG4-RD is the identification of characteristic histology and immunohistochemistry, which is the same regardless of organs involved (34). However, variation of histopathology can occur according to the stage of the disease. In longstanding IgG4-RD, the histology may become predominately fibrotic and confirmation of the diagnosis can be difficult (64). Repeated surgical or larger needle biopsies, instead of fine needle biopsies, or re-evaluation of earlier obtained archived tissue samples may help with diagnosis (Fig 1).

The three major histopathological features of IgG4-RD are: i) dense lymphoplasmacytic infiltrates, ii) storiform-type fibrosis of irregularly whorled pattern, resembling that of a straw mat, and iii) obliterative phlebitis. Sometimes formation of germinal centers and infiltration of 
eosinophils in affected tissues are observed (34).

Immunostaining for IgG4-positive plasma cells performed on biopsy specimens shows a rich infiltration of such cells, with variation between 11 and more than 200 of IgG4-positive cells counted per high power field (HPF). The number of IgG4-positive plasma cells more than 50 per HPF is considered highly specific, but different cut-offs are proposed for different tissues and surgical specimens (34). Inflammation can become "burned-out" in advanced IgG4related lesions. Therefore, staining for IgG-positive plasma cells should be performed. The ratio of $\operatorname{IgG} 4$ to $\operatorname{IgG}$ must be greater than 0.4 , and is mandatory for histological diagnosis of IgG4-RD (34).

The presence of granulomas, giant cells, necrosis, and neutrophilic microabscesses in biopsies strongly suggests an alternative diagnosis (34). Since malignant tumor is frequently suspected upon initial presentation of IgG4-RD, it should be always considered in the differential diagnosis.

It is often difficult to perform meningeal biopsy or biopsies of organs located in the thoracic and peritoneal cavities. Single case reports have shown that minor salivary gland biopsy, used as a method for diagnosis of SS (65), may show pathological features of IgG4-RD even without any clinical signs of involvement of these glands in the disease $(2,66)$. Another study reported that incisional biopsy of the submandibular gland is more appropriate for definitive diagnosis of IgG4-related sialoadenitis compared to minor salivary gland biopsy (67). However, the benefits of this diagnostic method in diagnosis of IgG4-RD should be evaluated in a larger cohort of patients.

\section{Organ manifestations and differential diagnosis}

More than 40 organs have been reported to be involved in IgG4-RD (68). Until very recently, only four cohorts of patients have been described $(6,38,69,70)$. A prospective study of 28 patients has shown multiple organ (2-4 sites) involvement in $93 \%$ of the patients (6). The 
largest cohort study so far of 125 patients with IgG4-RD, evaluated by rheumatologists with biopsy-proven disease, was reported recently (38). According to this study, the frequencies of the organ involvement include the following: submandibular glands $28 \%$, lymph nodes $27 \%$, orbit $22 \%$, pancreas $19 \%$, retroperitoneum $18 \%$, lung $18 \%$, parotid glands $17 \%$, kidney $12 \%$, aorta $11 \%$, biliary tract $10 \%$, ear $8 \%$, sinuses $4 \%$, nasal cavity $2.4 \%$, thyroid $5.6 \%$, prostate $3 \%$, meninges $2.4 \%$, liver $2.4 \%$, skin $1.6 \%$, heart $1.6 \%$, mesenterium $1.6 \%$, and other organs in lower frequencies.

\subsection{Salivary and lacrimal glands}

A continuous or recurrent painless uni- or bilateral swelling of the parotid and/or submandibular glands (sialadenitis) and/or upper eyelids (dacryoadenitis) with changes in facial appearance is particularly characteristic of $\operatorname{IgG} 4-\mathrm{RD}(27,71)$. In contrast to SS, patients with IgG4-related sialoadenitis/dacryodenitis (or so-called MD) have male dominance, more often involvement of submandibular than parotid glands, and mild symptoms of dry mouth/dry eyes. They are usually negative for anti-SS-A/SS-B antibodies, and respond rapidly to corticosteroids $(2,49)$. In addition, minor salivary gland biopsy reveals intact structure of salivary ducts despite lymphocytic infiltration and formation of lymphoid follicles, and immunostaining for IgG4-positive plasma cells helps further in differential diagnosis $(2,27,66)$. Thus, one cannot exclude that some patients previously diagnosed as incomplete or atypical SS may actually have undiagnosed IgG4-RD (20).

\subsection{Lymph nodes}

Lymphadenopathy can appear before, concurrent with, or after the diagnosis of IgG4-RD, and can be generalized or localized. The lymph nodes are non-tender and 1-3 cm in diameter $(71$, 72). Fibrosis is uncommon feature and is only seen in pseudotumor-like lymph nodes (34). Infections, lymphoma, carcinoma, and Castleman's disease should be considered in the differential diagnosis. 


\subsection{Ophthalmic and orbital lesions (pseudotumors)}

Orbital inflammation can involve extraocular muscles, orbital soft tissues, sclera, nasolacrimal duct, and trigeminal nerve, sometimes with bone destruction and development of a saddle nose deformity (73). The considerations in the differential for these patients include SS, granulomatosis with polyangiitis (GPA), sarcoidosis, lymphoma, infection, Graves' thyreotoxicosis, and cancer.

\subsection{Pancreas and biliary tract}

Type 1 AIP presents with painless jaundice, diabetes mellitus and/or abdominal pain (44). The diagnosis can be established by typical imaging, e.g., diffuse pancreatic enlargement with delayed enhancement, sometimes with the presence of "capsule-like rim" (57), and the presence of typical clinical symptoms with increased levels of IgG4 in serum. On the other hand, when imaging shows segmental swelling of pancreas or pancreatic duct dilatation, it is indistinguishable from adenocarcinoma. Further examination by endoscopic ultrasound or retrograde cholangiography and pathology confirmation are needed (44). Extrapancreatic manifestations are common with involvement of biliary tract, salivary glands, retroperitoneum, lung, mediastinum, lymph nodes, and kidney (74). In contrast to type 1 AIP, in type 2 AIP, which is associated with inflammatory bowel disease, normal concentrations of IgG and IgG4 in serum are observed, and granulocytic epithelial lesions with invasion of neutrophilic granulocytes are seen in biopsies.

IgG4-related sclerosing cholangitis is frequently associated with type 1 AIP. Solid mass lesions in hilar and perihilar ducts clinically and radiologically resemble primary sclerosing cholangitis or cholangiocarcinoma (75). IgG4-related cholecystitis may resemble biliary malignancy (76). Histopathology is crucial for differential diagnosis.

\subsection{Retroperitoneum}

The primary affected sites in IgG4-related retroperitoneal fibrosis (RF) are tissues around the 
abdominal aorta, branching arteries, and the ureters. The clinical presentation includes flank, back, scrotal or lower abdominal pain, swollen legs, hydronephrosis, and signs of renal insufficiency related to ureteral obstruction. Very few studies have been published on IgG4related RF. Thus, there is insufficient knowledge about clinical differences between idiopathic and IgG4-related RF, and the proportion of the patients diagnosed as idiopathic RF that may have undiagnosed IgG4-RD is unknown. Some patients with IgG4-related RF have higher serum IgG4 levels and involvement of other organs are detected at diagnosis (77). Typical imaging for type 1 AIP (57) with extrapancreatic involvement of retroperitoneum or mediastinal fibrosis may help diagnosis.

RF can be easily detected by CT or MRI imaging. The abdominal CT may reveal a thick rind of soft homogeneous tissue around the lower abdominal aorta and inferior vena cava between level of kidney and sacrum, not displacing aorta anteriorly. The ureters are generally displaced medially (78). An overlap between IgG4-related periaortitis and RF can occur, where the discrimination is dependent on the predominant location of lesions. In cases with periureteral or plaque-like lesions, the condition should be referred to as RF (60).

18F-FDG PET/CT imaging may help to visualize metabolic activity of active inflammation at the lesions, and can help to choose a biopsy site (62). The differential diagnosis is idiopathic and secondary RF caused by drugs, malignancy, Erdheim-Chester disease, infection, radiotherapy, and surgery (40). Although glucocorticoids are a mainstay of treatment of idiopathic and of IgG4-related RF, it is crucial to confirm IgG4-related RF by biopsy for further appropriate follow-up of the extent of the disease and the specific treatment.

\subsection{Lungs, pleura, and mediastinum}

IgG4-related lung disease may present with cough, hemoptysis, dyspnea, pleural effusion, and chest discomfort. The radiologic manifestations are often extensive even in the setting of mild clinical symptomatology (71). CT scan findings could be categorized into four major features: 
1) solid nodular densities; 2) round-shaped ground-glass opacities; 3) alveolar interstitial type with bronchiectasis resembling interstitial lung disease and pulmonary fibrosis with honeycombing; and 4) thickening of the bronchovascular bundles and interlobular septa (59). Other radiological features could also be seen in IgG4-related lung disease: mass density in mediastinum, nodular or diffuse pleural thickening, pleural effusion, and enlargement of regional lymph nodes (71). The diagnosis of IgG4-related lung disease can be difficult to differentiate from malignant tumors, sarcoidosis, multicentric Castleman's disease, GPA, or other inflammatory diseases.

Bronchoscopic or thoracoscopic biopsy of the lung, mass or pleura is indicated for establishing diagnosis. Histopathological examination shows typical features, often with obliterative phlebitis and arteritis, particularly in solid lesions; neutrophils and eosinophils may be present in alveolar spaces or within inflammatory infiltrates (34).

\subsection{Kidney}

IgG4-related kidney disease (IgG4-RKD) typically becomes apparent when renal dysfunction manifests or is detected accidentally by imaging showing multiple clearly demarcated lowdensity lesions, renal swelling, or thickening of renal pelvis wall (43). In some cases, enhanced CT or MRI may detect a "rim sign" of soft tissue around the kidney, like in type 1 AIP (58).

IgG4-RKD may present as tubulointerstitial nephritis (TIN), membranous glomerulonephritis (MGN) and pyelitis (79). Many patients with IgG4-RKD are ANA positive ( $>50 \%)$, but without specific antibodies (80). Hypergammaglobulinemia, elevated levels of IgG4 and IgE in serum, eosinophilia and hypocomplementemia are common laboratory findings. Most of the patients have also other organs involved at diagnosis $(43,77,81)$. Typical histological findings (34) with lymphoplasmacytic infiltration into and beyond the renal capsule reflect the “rim-like" lesions detected by CT in IgG4-related TIN (82). IgG4-related TIN may coexist 
sometimes with IgG4-MGN, and may be associated with proteinuria and hematuria (83). IgG4-TIN should be differentiated from drug-induced TIN. IgG4-related MGN is not associated with positivity for phospholipase A2 receptor antibody as primary MGN (80). Other differentials are idiopathic TIN, diabetic nephropathy, lupus-nephritis, SS-associated TIN, GPA, Castelman's disease, sarcoidosis, lymphoma, and malignancies. In most cases of IgG4-RKD, prompt response to glucocorticoids is observed. In cases in which the estimated glomerular filtration rate has already decreased to less than 60 before treatment, only partial recovery of renal function may be obtained (84).

\subsection{Heart and aorta}

\subsubsection{Pericardium}

IgG4-related constrictive pericarditis is characterized by clinical signs of right heart failure, marked pericardial thickening revealed by cardiac ultrasound or chest $\mathrm{CT}$, coexisting sometimes with mediastinal or retroperitoneal fibrosis (85). IgG4-positive plasma cells may infiltrate aortic valve causing aortic regurgitation and conduction abnormalities (86). Inflammation in the wall of aorta and coronary arteries or surrounding of the vessels may lead to aneurysmal changes and thrombosis (87), complicated by myocardial ischemia (88), aneurysm dissection or sudden death (89).

\subsubsection{IgG4-related periaortitis and/or periarteritis}

The most frequent symptoms of periaortitis/periarteritis may be abdominal and/or back pain, claudication, and low-grade fever. Characteristic radiological lesions with circumscribed thickening of arterial wall, with homogeneous enhancement at the late phase of contrast enhanced CT, associated with luminal changes, including aneurysmal dilatation, are seen (60). Inflammation and fibrosis may occur in the thoracic and abdominal aorta (90-92), large to medium-sized arteries, including iliac, renal, splenic, and mesenteric arteries (93) with formation of solitary aneurysm or in advanced disease multiple aneurysms (60). Among the 
three layers comprising the wall of aorta, the adventitia is most susceptible to IgG4-related inflammatory process, which can disrupt the lamellar elastic fibers in the media leading to aneurysmal transformation $(71,91)$. Involvement of other organs is seen in $70 \%$ of cases and overlap between IgG4-related periaortitis and retroperitoneal fibrosis can occur (60). The condition must be differentiated from lymphoma, atherosclerotic disease, infections (syphilis, HIV), and other inflammatory arteritis (Takayasu arteritis, Kawasaki disease). In extensive aneurysmal dilatation, surgery is the treatment of choice. It is thought that corticosteroids can exacerbate aneurysmal changes and increase the risk of aneurysmal rupture because of thinning of the arterial wall. However, in some cases, particularly with other organ involvement, a reduced dose of corticosteroids $(20 \mathrm{mg} /$ day $)$ can be used safely, not affecting aneurysmal diameter (60) and, in patients without luminal dilatation, even prevent new aneurysm formation (94).

\subsection{Upper airways}

Inflammation with swelling can appear in sinonasal cavity, sometimes with destructive lesions and saddle nose deformity. The fibrotic inflammations may spread to the middle ear and mastoid, pharynx, hypopharynx, Waldeyer's ring, vocal cord and trachea with development of subglottic stenosis (71). Differentials that need to be considered include lymphoma, solitary fibrous tumors, invasive aspergillosis, GPA and easinophilic GPA.

\subsection{Thyroid gland}

Hypothyroidism can be the first sign of IgG4-related thyroiditis. Enlargement of the thyroid gland can be unpalpable by physical examination in early disease, but can be revealed by CT or ultrasonography. The thyroid is easily accessible for biopsy. In the late stage of the disease, the thyroid gland becomes enlarged and fibrotic, sometimes extending into adjacent tissues and causing dyspnea and dysphagia. Riedel's thyroiditis and fibrosing variant of Hashimoto's thyroiditis appear to be members of the $\operatorname{Ig} 4-\operatorname{RD}(71,95)$. 


\subsection{Nerve system manifestations}

IgG4-related hypertrophic pachymeningitis with local dura matter involvement of the periorbital areas, vestibular structures, the clivus, brainstem, or spinal nerve roots causes focal signs such as visual or hearing impairment, cranial or spinal motor nerve palsies, and sensory alterations. More diffuse symptoms, such as headache, neck stiffness, and seizures, occur if meningeal inflammation spreads along the hemispheric and basal dura or the tentorium cerebelli. Differential diagnoses are GPA, neurosarcoidosis, and lymphoma.

On CT scans and MRI studies, pachymeningitis may appear either as a linear dural thickening or as a bulging mass. Cerebrospinal fluid evaluations are nonspecific and cannot differentiate IgG4-related pachymeningitis from other forms of inflammation. Biopsy material from the meninges is the gold standard for the diagnosis (96).

Clinical presentation of gG4-related hypophysitis depends of part of the pituitary affected and the size of the lesion. MRI is the best modality for assessing this condition, which appears as a thickened pituitary stalk or a pituitary region mass (71).

Brain parenchyma involvement is rare and can present with slowly progressive multifocal neurologic deficits and white substance lesions detected by MRI (97).

\subsection{Gastrointestinal tract}

Sclerosing mesenteritis involves small and/or large intestine with thickening of intestinal wall, adhesion to retropritoneum and surrounding arteries, and may be misdiagnosed as a cancer (98).

\subsection{Skin and joints}

Infiltration of IgG4-positive plasma cells presents as multiple red-brown papulonodular or indurative lesions, angiolymphoid hyperplasia with eosinophilia and pseudolymphoma localized on the periauricular, cheek and mandible regions. Psoriasis-like and erythematous eruptions without mass formation, palpable hypergammaglobulinemic purpura localized on 
the legs with leucocytoclastic or urticarial vasculitis may occur (99).

Differential diagnoses include systemic sclerosis, lupus erythematosus, antiphospholipid syndrome, SS, Henoch-Shönlein purpura, plasmacytosis, and psoriasis.

About $15 \%$ of patients with IgG4-RD may experience arthralgia (2), and sporadic patients may have arthritis caused by infiltration by IgG4-positive plasma cells in synovium (100). However, there have been limited studies and insufficient data, and no consensus on skin and joint lesions in IgG4-RD has emerged.

\section{Approach to treatment}

Recently, the international consensus guidance statement on the management and treatment of IgG4-RD has been published (101). However, no definitive treatment strategy for IgG4-RD has yet been established, and it varies even among specialists in IgG4-RD. Here some important current issues of the treatment of the disease are discussed with some novel insights into approaches.

\section{1 "Watch-and-wait" strategy}

In asymptomatic patients or those with limited disease, e.g., with only involvement of lymph nodes or salivary glands, "watch-and-wait" strategy can be applied (101). Follow-up of these patients is important by assessing organ dysfunction clinically and/or by imaging.

\subsection{Specific treatment}

In symptomatic patients glucocorticoids, and B-cell depletion for induction of remission are used. In some cases, surgical interventions are needed, and in severe cases, urgently.

\subsubsection{Glucocorticoids}

Systemic glucocorticoids, which are well known to induce nonselective apoptosis of lymphocytes, are the first-line approach for the most patients with symptomatic IgG4-RD. Most patients $(86-99 \%)(3,4,38)$ respond well to glucocorticoids within $2-4$ weeks. Two main steroid regimens, based on type 1 AIP and cholangitis treatment, have been employed 
for the management of IgG4-RD, even for other organ manifestations. A Japanese approach suggests an initial dose $0.5-0.6 \mathrm{mg} / \mathrm{kg} /$ day or fixed-dose of prednisone $30-40 \mathrm{mg} /$ day for $2-4$ weeks and then tapering by $5-10 \mathrm{mg}$ every $1-2$ weeks to low maintenance dose of prednisone $2.5-5 \mathrm{mg} /$ day, which is continued from 6 months up to 3 years $(3,4,102)$. Another approach established at the Mayo Clinic $(103,104)$ is an initial treatment with prednisone $40 \mathrm{mg} /$ day for 4 weeks and then tapering by $5 \mathrm{mg} /$ week during a 7 -week taper period until the patient is off prednisone by the end of 11 weeks. In clinical practice, higher prednisone doses may be needed to induce remission and to prevent major organ damage. Although glucocorticoids usually induce the remission in most cases, $25-50 \%$ of patients relapse on low maintenance dose or after discontinuation of glucocorticoids $(3,103)$.

\subsubsection{Steroid-sparing immunomodulators}

For remission-maintenance in relapsing IgG4-RD or as steroid-sparing approaches immunomodulators, such as mycophenalate mofetil (750 mg twice daily) and azathioprine $(2.0-2.5 \mathrm{mg} / \mathrm{kg} / \mathrm{day})(4,103)$, has been suggested. Some case reports have showed effectiveness of methotrexate (105), cyclosporine (106), and cyclophosphamide $(106,107)$. Further larger studies are needed to assess the efficacy to maintain remission with steroidsparing immunomodulators in IgG4-RD.

\subsubsection{Rituximab}

B-cell depletion with rituximab, used for the treatment of B-cell lymphoma, rheumatoid arthritis, and other autoimmune diseases, induces prompt clinical response to systemic IgG4$\mathrm{RD}(17,18)$, and is a better alternative than other immunomodulators in glucocorticoid resistant, generalized or relapsing disease. In patients with IgG4-RD, IgG4 concentrations in serum decline rapidly after rituximab treatment (17). A recently published prospective, openlabel pilot trial of 30 IgG4-RD patients treated with rituximab 2x1000 mg (administered 15 days apart) alone or discontinued baseline glucocorticoids within 2 months, has shown 
response to treatment in $97 \%$ of patients; thus, suggesting that even monotherapy with rituximab is effective in induction of remission (108). It is thought that the good efficacy of rituximab in IgG4-RD is achieved by apoptosis of short-lived plasma cells, producing IgG4 $(17,18)$, though the exact mechanism is not yet known.

Clinical trials regarding doses of rituximab, retreatment frequency, prognostic factors, and outcomes of treatment in different subtypes of IgG4-RD patients are warranted.

\subsubsection{Other possible specific therapies}

Bortezomib is a proteasome inhibitor, induces apoptosis of plasma cells, and impacts activated naïve and memory B cells (109). Bortezomib has been approved for the treatment of multiple myeloma, and appears to be effective also in transplantation settings by depleting anti-HLA antibody-producing plasma cells. Good effect of bortezimib has been reported in recurrent IgG4-related lung disease (110). Further studies are required to evaluate if bortezomib is effective in the treatment of recurrent IgG4-RD.

Effective therapies are needed to target fibrosis in advanced IgG4-RD. As in other fibrotic conditions (e.g., systemic sclerosis, idiopathic pulmonary fibrosis), there is currently no accepted potentially effective anti-fibrotic treatment. Targeting multiple regulatory pathways involving growth factors and cytokines (21), which are involved in activation of myofibroblasts and fibroproliferation, are required.

Antihistamines in allergic IgG4-RD patients may play a positive role by changing cytokine milieu. Targeting selectively histamine H4 receptors the inhibition of mast cells and eosinophils (111) with potential immunomodulating benefit may be achieved.

Tamoxifen, used for breast cancer, has modulating effects on apoptotic signaling proteins (112). In addition to glucocorticoids, tamoxifen is another therapeutic option for treatment of idiopathic RF (113), and can be used as a second-line drug, particularly for patients who cannot tolerate glucocorticoids. However, the efficacy and safety of the drug are not known in 
IgG4-related RF.

\subsection{Operative approaches and radiation therapy}

The large number of patients with IgG4-RD can be detected when undergoing surgical procedures before diagnosis (38). Ureteral and biliary balloon dilatation, stent placement (38), endovascular aortic repair (94), palliative surgical bypass (4), and surgical excision (107) can be required as urgent surgical interventions. In some cases of orbital pseudotumor, radiotherapy can be used to achieve remission (107).

\subsection{Follow-up}

Responses to therapy to follow-up are clinical improvement, reduction of organ swelling observed clinically, or by follow-up imaging, detection of decreasing concentration of IgG4 in serum, and normalized laboratory tests. IgG4-RD responder index to define response to treatment, remission, and relapse has been developed (114) and can be applied also in clinical practice.

\section{Conclusion}

IgG4-RD may have many "faces" with multi-organ involvement, and has a chronic recurrent course. The condition is often not recognized in early stages and, if left untreated, leads to irreversible fibrosis and organ dysfunction. Clinicians in various specialties should be aware of the disease. The early detection of the disorder can be effectively managed by immunosuppressive therapies. While glucocorticoids are widely used for the treatment of the disease, prolonged glucocorticoid use may have many adverse side effects, and it seems to be a temporary solution. Large clinical trials are required for studying targeted therapies (e.g., rituximab, bortezomib) and combined therapies in different subsets and different clinical manifestations of patients with IgG4-RD.

\section{Conflict of interests}


The authors state that they have no conflict of interests.

\section{Acknowledgments}

I would like to thank Diem Nguyen and Michelle Cleary, $\mathrm{PhD}$ for language revision and the Lions Cancerforskningsfond, scholarships from Agnes\&Mac Rudbergs and Gustav Prims Reumatikerfond foundations for supporting this work. The author thanks six anonymous reviewers for their constructive comments on the manuscript.

\section{References}

1. Kamisawa T, Funata N, Hayashi Y, Eishi Y, Koike M, Tsuruta K, et al. A new clinicopathological entity of IgG4-related autoimmune disease. J Gastroenterol. 2003;38(10):982-4. PubMed PMID: 14614606. Epub 2003/11/14. eng.

2. Masaki Y, Dong L, Kurose N, Kitagawa K, Morikawa Y, Yamamoto M, et al. Proposal for a new clinical entity, IgG4-positive multiorgan lymphoproliferative syndrome: analysis of 64 cases of IgG4-related disorders. Annals of the rheumatic diseases. 2009 Aug;68(8):1310-5. PubMed PMID: 18701557. Epub 2008/08/15. eng.

3. Kamisawa T, Shimosegawa T, Okazaki K, Nishino T, Watanabe H, Kanno A, et al. Standard steroid treatment for autoimmune pancreatitis. Gut. 2009 Nov;58(11):1504-7. PubMed PMID: 19398440. Epub 2009/04/29. eng.

4. Hart PA, Kamisawa T, Brugge WR, Chung JB, Culver EL, Czako L, et al. Long-term outcomes of autoimmune pancreatitis: a multicentre, international analysis. Gut. 2013 Dec;62(12):1771-6. PubMed PMID: 23232048. Pubmed Central PMCID: 3862979. 5. Della Torre E, Mattoo H, Mahajan VS, Carruthers M, Pillai S, Stone JH. Prevalence of atopy, eosinophilia, and IgE elevation in IgG4-related disease. Allergy. 2014 Feb;69(2):269-72. PubMed PMID: 24266692. 
Chinese cohort: a prospective study. Scandinavian journal of rheumatology. 2014;43(1):70-4. PubMed PMID: 24134471. Epub 2013/10/19. eng.

7. Nirula A, Glaser SM, Kalled SL, Taylor FR. What is IgG4? A review of the biology of a unique immunoglobulin subtype. Current opinion in rheumatology. 2011 Jan;23(1):119-24. PubMed PMID: 21124094. Epub 2010/12/03. eng.

8. Tanaka A, Moriyama M, Nakashima H, Miyake K, Hayashida JN, Maehara T, et al. Th2 and regulatory immune reactions contribute to IgG4 production and the initiation of Mikulicz disease. Arthritis and rheumatism. 2012 Jan;64(1):254-63. PubMed PMID: 21898360. Epub 2011/09/08. eng.

9. Tsuboi H, Matsuo N, Iizuka M, Tsuzuki S, Kondo Y, Tanaka A, et al. Analysis of IgG4 class switch-related molecules in IgG4-related disease. Arthritis research \& therapy. 2012;14(4):R171. PubMed PMID: 22824292. Pubmed Central PMCID: 3580565. Epub 2012/07/25. eng.

10. Takeuchi M, Sato Y, Ohno K, Tanaka S, Takata K, Gion Y, et al. T helper 2 and regulatory T-cell cytokine production by mast cells: a key factor in the pathogenesis of IgG4related disease. Modern pathology : an official journal of the United States and Canadian Academy of Pathology, Inc. 2014 Aug;27(8):1126-36. PubMed PMID: 24390219. Epub 2014/01/07. eng.

11. Shevach EM, DiPaolo RA, Andersson J, Zhao DM, Stephens GL, Thornton AM. The lifestyle of naturally occurring CD4+CD25+ Foxp3+ regulatory T cells. Immunol Rev. 2006 Aug;212:60-73. PubMed PMID: 16903906. Epub 2006/08/15. eng. 12. Meiler F, Klunker S, Zimmermann M, Akdis CA, Akdis M. Distinct regulation of IgE, IgG4 and IgA by T regulatory cells and toll-like receptors. Allergy. 2008 Nov;63(11):1455-63. PubMed PMID: 18925882. Epub 2008/10/18. eng. 
13.

Satoh-Nakamura T, Kurose N, Kawanami T, Nakamura T, Iwao-Kawanami H, Nakajima A, et al. CD14+ follicular dendritic cells in lymphoid follicles may play a role in the pathogenesis of IgG4-related disease. Biomedical research. 2015;36(2):143-53. PubMed PMID: 25876665.

14. Medina F, Segundo C, Campos-Caro A, Gonzalez-Garcia I, Brieva JA. The heterogeneity shown by human plasma cells from tonsil, blood, and bone marrow reveals graded stages of increasing maturity, but local profiles of adhesion molecule expression. Blood. 2002 Mar 15;99(6):2154-61. PubMed PMID: 11877292.

15.

Wallace ZS, Mattoo H, Carruthers M, Mahajan VS, Della Torre E, Lee H, et al. Plasmablasts as a biomarker for IgG4-related disease, independent of serum IgG4 concentrations. Annals of the rheumatic diseases. 2015 Jan;74(1):190-5. PubMed PMID: 24817416. Epub 2014/05/13. eng.

16.

Mattoo H, Mahajan VS, Della-Torre E, Sekigami Y, Carruthers M, Wallace ZS, et al. De novo oligoclonal expansions of circulating plasmablasts in active and relapsing IgG4-related disease. The Journal of allergy and clinical immunology. 2014 Sep;134(3):67987. PubMed PMID: 24815737. Pubmed Central PMCID: 4149918. Epub 2014/05/13. eng. 17. Khosroshahi A, Bloch DB, Deshpande V, Stone JH. Rituximab therapy leads to rapid decline of serum IgG4 levels and prompt clinical improvement in IgG4-related systemic disease. Arthritis and rheumatism. 2010 Jun;62(6):1755-62. PubMed PMID: 20191576. Epub 2010/03/02. eng.

18. Khosroshahi A, Carruthers MN, Deshpande V, Unizony S, Bloch DB, Stone JH. Rituximab for the treatment of IgG4-related disease: lessons from 10 consecutive patients. Medicine. 2012 Jan;91(1):57-66. PubMed PMID: 22210556. Epub 2012/01/03. eng. 19. Mattoo H, Della-Torre E, Mahajan VS, Stone JH, Pillai S. Circulating Th2 memory cells in IgG4-related disease are restricted to a defined subset of subjects with atopy. 
Allergy. 2014 Mar;69(3):399-402. PubMed PMID: 24382311. Pubmed Central PMCID: 3944385. Epub 2014/01/03. eng.

20. Moriyama M, Tanaka A, Maehara T, Furukawa S, Nakashima H, Nakamura S. T helper subsets in Sjogren's syndrome and IgG4-related dacryoadenitis and sialoadenitis: a critical review. Journal of autoimmunity. 2014 Jun;51:81-8. PubMed PMID: 23920005. Epub 2013/08/08. eng.

21. Rosenbloom J, Mendoza FA, Jimenez SA. Strategies for anti-fibrotic therapies. Biochimica et biophysica acta. 2013 Jul;1832(7):1088-103. PubMed PMID: 23266403. 22. Bruhns P, Iannascoli B, England P, Mancardi DA, Fernandez N, Jorieux S, et al. Specificity and affinity of human Fcgamma receptors and their polymorphic variants for human IgG subclasses. Blood. 2009 Apr 16;113(16):3716-25. PubMed PMID: 19018092. 23. Aalberse RC, Stapel SO, Schuurman J, Rispens T. Immunoglobulin G4: an odd antibody. Clin Exp Allergy. 2009 Apr;39(4):469-77. PubMed PMID: 19222496. Epub 2009/02/19. eng.

24. van der Neut Kolfschoten M, Schuurman J, Losen M, Bleeker WK, MartinezMartinez P, Vermeulen E, et al. Anti-inflammatory activity of human IgG4 antibodies by dynamic Fab arm exchange. Science. 2007 Sep 14;317(5844):1554-7. PubMed PMID: 17872445. Epub 2007/09/18. eng.

25. Aalberse RC, van der Gaag R, van Leeuwen J. Serologic aspects of IgG4 antibodies. I. Prolonged immunization results in an IgG4-restricted response. J Immunol. 1983 Feb;130(2):722-6. PubMed PMID: 6600252. Epub 1983/02/01. eng. 26. Morgan WS, Castleman B. A clinicopathologic study of Mikulicz's disease. The American journal of pathology. 1953 May-Jun;29(3):471-503. PubMed PMID: 13040489. Pubmed Central PMCID: 1937437. 
Clinical and pathological differences between Mikulicz's disease and Sjogren's syndrome. Rheumatology. 2005 Feb;44(2):227-34. PubMed PMID: 15509627. Epub 2004/10/29. eng. 28. Sarles H, Sarles JC, Muratore R, Guien C. Chronic inflammatory sclerosis of the pancreas--an autonomous pancreatic disease? Am J Dig Dis. 1961 Jul;6:688-98. PubMed PMID: 13746542. Epub 1961/07/01. eng.

29. Yoshida K, Toki F, Takeuchi T, Watanabe S, Shiratori K, Hayashi N. Chronic pancreatitis caused by an autoimmune abnormality. Proposal of the concept of autoimmune pancreatitis. Dig Dis Sci. 1995 Jul;40(7):1561-8. PubMed PMID: 7628283. Epub 1995/07/01. eng.

30. Hamano H, Kawa S, Horiuchi A, Unno H, Furuya N, Akamatsu T, et al. High serum IgG4 concentrations in patients with sclerosing pancreatitis. N Engl J Med. 2001 Mar 8;344(10):732-8. PubMed PMID: 11236777. Epub 2001/03/10. eng.

31. Hamano H, Kawa S, Ochi Y, Unno H, Shiba N, Wajiki M, et al. Hydronephrosis associated with retroperitoneal fibrosis and sclerosing pancreatitis. Lancet. $2002 \mathrm{Apr}$ 20;359(9315):1403-4. PubMed PMID: 11978339. Epub 2002/04/30. eng.

32. Kamisawa T, Egawa N, Nakajima H. Autoimmune pancreatitis is a systemic autoimmune disease. Am J Gastroenterol. 2003 Dec;98(12):2811-2. PubMed PMID: 14687846. Epub 2003/12/23. eng. al. Recommendations for the nomenclature of IgG4-related disease and its individual organ system manifestations. Arthritis and rheumatism. 2012 Oct;64(10):3061-7. PubMed PMID: 22736240. Epub 2012/06/28. eng.

34. Deshpande V, Zen Y, Chan JK, Yi EE, Sato Y, Yoshino T, et al. Consensus statement on the pathology of IgG4-related disease. Modern pathology : an official journal of 
the United States and Canadian Academy of Pathology, Inc. 2012 Sep;25(9):1181-92. PubMed PMID: 22596100. Epub 2012/05/19. eng.

35. Umehara H, Okazaki K, Masaki Y, Kawano M, Yamamoto M, Saeki T, et al. A novel clinical entity, IgG4-related disease (IgG4RD): general concept and details. Modern rheumatology / the Japan Rheumatism Association. 2012 Feb;22(1):1-14. PubMed PMID: 21881964. Pubmed Central PMCID: 3278618. Epub 2011/09/02. eng.

36. Uchida K, Masamune A, Shimosegawa T, Okazaki K. Prevalence of IgG4Related Disease in Japan Based on Nationwide Survey in 2009. International journal of rheumatology. 2012;2012:358371. PubMed PMID: 22899936. Pubmed Central PMCID: 3415093.

37. Yamamoto M, Yajima H, Takahashi H, Yokoyama Y, Ishigami K, Shimizu Y, et al. Everyday clinical practice in IgG4-related dacryoadenitis and/or sialadenitis: Results from the SMART database. Modern rheumatology / the Japan Rheumatism Association. 2014 Aug 27:1-6. PubMed PMID: 25159154. Epub 2014/08/28. Eng.

38. Wallace ZS, Deshpande V, Mattoo H, Mahajan VS, Kulikova M, Pillai S, et al. IgG4-related disease: Clinical and laboratory features in 125 patients. Arthritis \& rheumatology. 2015 May 18. PubMed PMID: 25988916.

39. Mannion M, Cron RQ. Successful treatment of pediatric IgG4 related systemic disease with mycophenolate mofetil: case report and a review of the pediatric autoimmune pancreatitis literature. Pediatr Rheumatol Online J. 2011;9(1):1. PubMed PMID: 21205323. Pubmed Central PMCID: 3022838. Epub 2011/01/06. eng.

40. Laco J, Podhola M, Kamaradova K, Novak I, Dobes D, Brodak M, et al. Idiopathic vs. secondary retroperitoneal fibrosis: a clinicopathological study of 12 cases, with emphasis to possible relationship to IgG4-related disease. Virchows Arch. 2013 Nov;463(5):721-30. PubMed PMID: 24052251. Epub 2013/09/21. eng. 
IgG4 orbital inflammation in a 5-year-old child presenting as an orbital mass. Orbit. 2013 Apr;32(2):137-40. PubMed PMID: 23480695. Epub 2013/03/14. eng.

42. Umehara H, Okazaki K, Masaki Y, Kawano M, Yamamoto M, Saeki T, et al. Comprehensive diagnostic criteria for IgG4-related disease (IgG4-RD), 2011. Modern rheumatology / the Japan Rheumatism Association. 2012 Feb;22(1):21-30. PubMed PMID: 22218969. Epub 2012/01/06. eng.

43. Kawano M, Saeki T, Nakashima H, Nishi S, Yamaguchi Y, Hisano S, et al. Proposal for diagnostic criteria for IgG4-related kidney disease. Clin Exp Nephrol. 2011 Oct;15(5):615-26. PubMed PMID: 21898030.

44. Shimosegawa T, Chari ST, Frulloni L, Kamisawa T, Kawa S, Mino-Kenudson $\mathrm{M}$, et al. International consensus diagnostic criteria for autoimmune pancreatitis: guidelines of the International Association of Pancreatology. Pancreas. 2011 Apr;40(3):352-8. PubMed PMID: 21412117.

45. Yamamoto M, Takahashi H, Shinomura Y. Mechanisms and assessment of IgG4-related disease: lessons for the rheumatologist. Nature reviews Rheumatology. 2014 Mar;10(3):148-59. PubMed PMID: 24296677. Epub 2013/12/04. eng.

46. Cheuk W, Yuen HK, Chan AC, Shih LY, Kuo TT, Ma MW, et al. Ocular adnexal lymphoma associated with IgG4+ chronic sclerosing dacryoadenitis: a previously undescribed complication of IgG4-related sclerosing disease. Am J Surg Pathol. 2008 Aug;32(8):1159-67. PubMed PMID: 18580683. Epub 2008/06/27. eng. 47. Oyama T, Takizawa J, Nakamura N, Aoki S, Aizawa Y, Abe H. Multifocal mucosa-associated lymphoid tissue lymphoma associated with IgG4-related disease: a case report. Japanese journal of ophthalmology. 2011 May;55(3):304-6. PubMed PMID: 21584726. Epub 2011/05/18. eng. 
Marginal zone lymphomas involving meningeal dura: possible link to IgG4-related diseases. Modern pathology : an official journal of the United States and Canadian Academy of Pathology, Inc. 2011 Mar;24(3):355-66. PubMed PMID: 21102421. Epub 2010/11/26. eng. 49. Takahashi H, Yamamoto M, Tabeya T, Suzuki C, Naishiro Y, Shinomura Y, et al. The immunobiology and clinical characteristics of IgG4 related diseases. Journal of autoimmunity. 2012 Aug;39(1-2):93-6. PubMed PMID: 22341851.

50.

Kiyama K, Yoshifuji H, Kandou T, Hosono Y, Kitagori K, Nakashima R, et al. Screening for IgG4-type anti-nuclear antibodies in IgG4-related disease. BMC musculoskeletal disorders. 2015;16:129. PubMed PMID: 26018403. Pubmed Central PMCID: 4447006.

51. Masaki Y, Kurose N, Yamamoto M, Takahashi H, Saeki T, Azumi A, et al. Cutoff Values of Serum IgG4 and Histopathological IgG4+ Plasma Cells for Diagnosis of Patients with IgG4-Related Disease. International journal of rheumatology. 2012;2012:580814. PubMed PMID: 22654917. Pubmed Central PMCID: 3357966. Epub 2012/06/02. eng.

52. Carruthers MN, Khosroshahi A, Augustin T, Deshpande V, Stone JH. The diagnostic utility of serum IgG4 concentrations in IgG4-related disease. Annals of the rheumatic diseases. 2015 Jan;74(1):14-8. PubMed PMID: 24651618. Epub 2014/03/22. eng. 53. Geyer JT, Niesvizky R, Jayabalan DS, Mathew S, Subramaniyam S, Geyer AI, et al. IgG4 plasma cell myeloma: new insights into the pathogenesis of IgG4-related disease. Modern pathology : an official journal of the United States and Canadian Academy of Pathology, Inc. 2014 Mar;27(3):375-81. PubMed PMID: 24030741. Epub 2013/09/14. eng. 54. Ebbo M, Grados A, Bernit E, Vely F, Boucraut J, Harle JR, et al. Pathologies Associated with Serum IgG4 Elevation. International journal of rheumatology. 
2012;2012:602809. PubMed PMID: 22966232. Pubmed Central PMCID: 3433130. Epub 2012/09/12. eng.

55. Su Y, Sun W, Wang C, Wu X, Miao Y, Xiong H, et al. Detection of serum IgG4 levels in patients with IgG4-related disease and other disorders. PloS one. 2015;10(4):e0124233. PubMed PMID: 25885536. Pubmed Central PMCID: 4401680.

56. Khosroshahi A, Cheryk LA, Carruthers MN, Edwards JA, Bloch DB, Stone JH. Brief Report: spuriously low serum IgG4 concentrations caused by the prozone phenomenon in patients with IgG4-related disease. Arthritis \& rheumatology. 2014 Jan;66(1):213-7. PubMed PMID: 24431286. Epub 2014/01/17. eng.

57. Chari ST, Takahashi N, Levy MJ, Smyrk TC, Clain JE, Pearson RK, et al. A diagnostic strategy to distinguish autoimmune pancreatitis from pancreatic cancer. Clinical gastroenterology and hepatology : the official clinical practice journal of the American Gastroenterological Association. 2009 Oct;7(10):1097-103. PubMed PMID: 19410017. 58. Takahashi N, Kawashima A, Fletcher JG, Chari ST. Renal involvement in patients with autoimmune pancreatitis: CT and MR imaging findings. Radiology. 2007 Mar;242(3):791-801. PubMed PMID: 17229877.

59. Inoue D, Zen Y, Abo H, Gabata T, Demachi H, Kobayashi T, et al. Immunoglobulin G4-related lung disease: CT findings with pathologic correlations. Radiology. 2009 Apr;251(1):260-70. PubMed PMID: 19221056. Epub 2009/02/18. eng. 60. Inoue D, Zen Y, Abo H, Gabata T, Demachi H, Yoshikawa J, et al. Immunoglobulin G4-related periaortitis and periarteritis: CT findings in 17 patients. Radiology. 2011 Nov;261(2):625-33. PubMed PMID: 21803920. Epub 2011/08/02. eng. 61. Katsura M, Mori H, Kunimatsu A, Sasaki H, Abe O, Machida T, et al. Radiological features of IgG4-related disease in the head, neck, and brain. Neuroradiology. 2012 Aug;54(8):873-82. PubMed PMID: 22358111. Epub 2012/02/24. eng. 

systemic disease. Clin Radiol. 2012 Apr;67(4):297-305. PubMed PMID: 22119099. Epub 2011/11/29. eng.

63. Ebbo M, Grados A, Guedj E, Gobert D, Colavolpe C, Zaidan M, et al. Usefulness of 2-[18F]-fluoro-2-deoxy-D-glucose-positron emission tomography/computed tomography for staging and evaluation of treatment response in IgG4-related disease: a retrospective multicenter study. Arthritis care \& research. 2014 Jan;66(1):86-96. PubMed PMID: 23836437. Epub 2013/07/10. eng.

64. Shimizu Y, Yamamoto M, Naishiro Y, Sudoh G, Ishigami K, Yajima H, et al. Necessity of early intervention for IgG4-related disease--delayed treatment induces fibrosis progression. Rheumatology. 2013 Apr;52(4):679-83. PubMed PMID: 23258649. Epub 2012/12/22. eng.

65. Chisholm DM, Mason DK. Labial salivary gland biopsy in Sjogren's disease. Journal of clinical pathology. 1968 Sep;21(5):656-60. PubMed PMID: 5697370. Pubmed Central PMCID: 473887. Epub 1968/09/01. eng.

66. Doe K, Nozawa K, Okada T, Tada K, Yamaji K, Tamura N, et al. Usefulness of minor salivary gland biopsy in the diagnosis of IgG4-related disease: a case report. Int J Clin Exp Pathol. 2014;7(5):2673-7. PubMed PMID: 24966985. Pubmed Central PMCID: 4069935. Epub 2014/06/27. eng.

67. Moriyama M, Furukawa S, Kawano S, Goto Y, Kiyoshima T, Tanaka A, et al. The diagnostic utility of biopsies from the submandibular and labial salivary glands in IgG4related dacryoadenitis and sialoadenitis, so-called Mikulicz's disease. Int J Oral Maxillofac Surg. 2014 Oct;43(10):1276-81. PubMed PMID: 25062551. Epub 2014/07/27. eng. 
68. Brito-Zeron P, Ramos-Casals M, Bosch X, Stone JH. The clinical spectrum of IgG4-related disease. Autoimmunity reviews. 2014 Dec;13(12):1203-10. PubMed PMID: 25151972. Epub 2014/08/26. Eng.

69.

Ebbo M, Daniel L, Pavic M, Seve P, Hamidou M, Andres E, et al. IgG4-related systemic disease: features and treatment response in a French cohort: results of a multicenter registry. Medicine. 2012 Jan;91(1):49-56. PubMed PMID: 22198501. Epub 2011/12/27. eng. 70. Zen Y, Nakanuma Y. IgG4-related disease: a cross-sectional study of 114 cases. The American journal of surgical pathology. 2010 Dec;34(12):1812-9. PubMed PMID: 21107087.

71.

Mahajan VS, Mattoo H, Deshpande V, Pillai SS, Stone JH. IgG4-related disease. Annual review of pathology. 2014;9:315-47. PubMed PMID: 24111912. Epub 2013/10/12. eng.

72. Sato Y, Kojima M, Takata K, Morito T, Asaoku H, Takeuchi T, et al. Systemic IgG4-related lymphadenopathy: a clinical and pathologic comparison to multicentric Castleman's disease. Modern pathology : an official journal of the United States and Canadian Academy of Pathology, Inc. 2009 Apr;22(4):589-99. PubMed PMID: 19270642. Epub 2009/03/10. eng.

73. Wallace ZS, Deshpande V, Stone JH. Ophthalmic manifestations of IgG4related disease: single-center experience and literature review. Seminars in arthritis and rheumatism. 2014 Jun;43(6):806-17. PubMed PMID: 24513111. Epub 2014/02/12. eng. 74. Matsubayashi H, Kakushima N, Takizawa K, Tanaka M, Imai K, Hotta K, et al. Diagnosis of autoimmune pancreatitis. World journal of gastroenterology : WJG. 2014 Nov 28;20(44):16559-69. PubMed PMID: 25469024. Pubmed Central PMCID: 4248199. 
Diagnostic criteria for IgG4-related sclerosing cholangitis based on cholangiographic classification. Journal of gastroenterology. 2012 Jan;47(1):79-87. PubMed PMID: 21947649. 76. Feely MM, Gonzalo DH, Corbera M, Hughes SJ, Trevino JG. IgG4-related cholecystitis presenting as biliary malignancy: report of three cases. Journal of gastrointestinal surgery : official journal of the Society for Surgery of the Alimentary Tract. 2014 Sep;18(9):1710-5. PubMed PMID: 24944152.

77. Kawa S, Ito T, Watanabe T, Maruyama M, Hamano H, Maruyama M, et al. The Utility of Serum IgG4 Concentrations as a Biomarker. International journal of rheumatology. 2012;2012:198314. PubMed PMID: 22536256. Pubmed Central PMCID: 3321274.

78. Vaglio A, Palmisano A, Corradi D, Salvarani C, Buzio C. Retroperitoneal fibrosis: evolving concepts. Rheumatic diseases clinics of North America. 2007 Nov;33(4):803-17, vi-vii. PubMed PMID: 18037118.

79. Saeki T, Kawano M. IgG4-related kidney disease. Kidney international. 2014 Feb;85(2):251-7. PubMed PMID: 24107849.

80. Khosroshahi A, Ayalon R, Beck LH, Jr., Salant DJ, Bloch DB, Stone JH. IgG4Related Disease Is Not Associated with Antibody to the Phospholipase A2 Receptor. International journal of rheumatology. 2012;2012:139409. PubMed PMID: 22654915. Pubmed Central PMCID: 3357948.

81. Saeki T, Nishi S, Imai N, Ito T, Yamazaki H, Kawano M, et al.

Clinicopathological characteristics of patients with IgG4-related tubulointerstitial nephritis. Kidney Int. 2010 Nov;78(10):1016-23. PubMed PMID: 20720530. Epub 2010/08/20. eng. 82. Yoshita K, Kawano M, Mizushima I, Hara S, Ito Y, Imai N, et al. Lightmicroscopic characteristics of IgG4-related tubulointerstitial nephritis: distinction from nonIgG4-related tubulointerstitial nephritis. Nephrology, dialysis, transplantation : official 
publication of the European Dialysis and Transplant Association - European Renal Association. 2012 Jul;27(7):2755-61. PubMed PMID: 22228836.

83.

Alexander MP, Larsen CP, Gibson IW, Nasr SH, Sethi S, Fidler ME, et al.

Membranous glomerulonephritis is a manifestation of IgG4-related disease. Kidney international. 2013 Mar;83(3):455-62. PubMed PMID: 23254897.

84. Saeki T, Kawano M, Mizushima I, Yamamoto M, Wada Y, Nakashima H, et al. The clinical course of patients with IgG4-related kidney disease. Kidney Int. 2013 Oct;84(4):826-33. PubMed PMID: 23698232. Epub 2013/05/24. eng.

85. Sugimoto T, Morita Y, Isshiki K, Yamamoto T, Uzu T, Kashiwagi A, et al. Constrictive pericarditis as an emerging manifestation of hyper-IgG4 disease. Int J Cardiol. 2008 Nov 28;130(3):e100-1. PubMed PMID: 17727980. Epub 2007/08/31. eng. 86. Yamauchi H, Satoh H, Yamashita T, Shinshi Y, Kikuchi K, Sasaki S, et al. Immunoglobulin G4-related disease of the heart causing aortic regurgitation and heart block. The Annals of thoracic surgery. 2013 Jun;95(6):e151-3. PubMed PMID: 23706467. Epub 2013/05/28. eng.

87. Matsumoto Y, Kasashima S, Kawashima A, Sasaki H, Endo M, Kawakami K, et al. A case of multiple immunoglobulin G4-related periarteritis: a tumorous lesion of the coronary artery and abdominal aortic aneurysm. Human pathology. 2008 Jun;39(6):975-80. PubMed PMID: 18430457. Epub 2008/04/24. eng.

88. Tanigawa J, Daimon M, Murai M, Katsumata T, Tsuji M, Ishizaka N. Immunoglobulin G4-related coronary periarteritis in a patient presenting with myocardial ischemia. Human pathology. 2012 Jul;43(7):1131-4. PubMed PMID: 22401772. Epub 2012/03/10. eng.

89. Gutierrez PS, Schultz T, Siqueira SA, de Figueiredo Borges L. Sudden coronary death due to IgG4-related disease. Cardiovascular pathology : the official journal of the 
Society for Cardiovascular Pathology. 2013 Nov-Dec;22(6):505-7. PubMed PMID: 23830124. Epub 2013/07/09. eng.

90. Kasashima S, Zen Y, Kawashima A, Endo M, Matsumoto Y, Kasashima F, et al. A clinicopathologic study of immunoglobulin G4-related sclerosing disease of the thoracic aorta. J Vasc Surg. 2010 Dec;52(6):1587-95. PubMed PMID: 20678882. Epub 2010/08/04. eng.

91. Kasashima S, Zen Y, Kawashima A, Konishi K, Sasaki H, Endo M, et al. Inflammatory abdominal aortic aneurysm: close relationship to IgG4-related periaortitis. Am J Surg Pathol. 2008 Feb;32(2):197-204. PubMed PMID: 18223321. Epub 2008/01/29. eng. 92. Agaimy A, Weyand M, Strecker T. Inflammatory thoracic aortic aneurysm (lymphoplasmacytic thoracic aortitis): a 13-year-experience at a German Heart Center with emphasis on possible role of IgG4. Int J Clin Exp Pathol. 2013;6(9):1713-22. PubMed PMID: 24040436. Pubmed Central PMCID: 3759478. Epub 2013/09/17. eng.

93. Zen Y, Kasashima S, Inoue D. Retroperitoneal and aortic manifestations of immunoglobulin G4-related disease. Semin Diagn Pathol. 2012 Nov;29(4):212-8. PubMed PMID: 23068300. Epub 2012/10/17. eng.

94. Mizushima I, Inoue D, Yamamoto M, Yamada K, Saeki T, Ubara Y, et al. Clinical course after corticosteroid therapy in IgG4-related aortitis/periaortitis and periarteritis: a retrospective multicenter study. Arthritis research \& therapy. 2014;16(4):R156. PubMed PMID: 25056443. Pubmed Central PMCID: 4220557.

95. Deshpande V, Huck A, Ooi E, Stone JH, Faquin WC, Nielsen GP. Fibrosing variant of Hashimoto thyroiditis is an IgG4 related disease. Journal of clinical pathology. 2012 Aug;65(8):725-8. PubMed PMID: 22659333. Epub 2012/06/05. eng. 
pachymeningitis: clinical features, diagnostic criteria, and treatment. JAMA neurology. 2014 Jun;71(6):785-93. PubMed PMID: 24733677. Epub 2014/04/16. eng.

97. Regev K, Nussbaum T, Cagnano E, Giladi N, Karni A. Central nervous system manifestation of IgG4-related disease. JAMA neurology. 2014 Jun;71(6):767-70. PubMed PMID: 24781034. Epub 2014/05/02. eng.

98. Minato H, Shimizu J, Arano Y, Saito K, Masunaga T, Sakashita T, et al. IgG4related sclerosing mesenteritis: a rare mesenteric disease of unknown etiology. Pathology international. 2012 Apr;62(4):281-6. PubMed PMID: 22449233.

99. Tokura Y, Yagi H, Yanaguchi H, Majima Y, Kasuya A, Ito T, et al. IgG4related skin disease. The British journal of dermatology. 2014 Nov;171(5):959-67. PubMed PMID: 25065694.

100. Umekita K, Kaneko Y, Yorita K, Hashiba Y, Matsuda M, Miyauchi S, et al. Arthropathy with infiltrate IgG4-positive plasma cells in synovium. Rheumatology. 2012 Mar;51(3):580-2. PubMed PMID: 22120458. Epub 2011/11/29. eng.

101. Khosroshahi A, Wallace ZS, Crowe JL, Akamizu T, Azumi A, Carruthers MN, et al. International Consensus Guidance Statement on the Management and Treatment of IgG4-Related Disease. Arthritis \& rheumatology. 2015 Jul;67(7):1688-99. PubMed PMID: 25809420.

102. Masaki Y, Shimizu H, Sato Nakamura T, Nakamura T, Nakajima A, Iwao Kawanami H, et al. IgG4-related disease: diagnostic methods and therapeutic strategies in Japan. Journal of clinical and experimental hematopathology : JCEH. 2014;54(2):95-101. PubMed PMID: 25318941. 
103. Ghazale A, Chari ST, Zhang L, Smyrk TC, Takahashi N, Levy MJ, et al. Immunoglobulin G4-associated cholangitis: clinical profile and response to therapy. Gastroenterology. 2008 Mar;134(3):706-15. PubMed PMID: 18222442.

104. Pannala R, Chari ST. Corticosteroid treatment for autoimmune pancreatitis. Gut. 2009 Nov;58(11):1438-9. PubMed PMID: 19834112.

105. Hyun JW, Kim SH, Yoo H, Hong EK, Huh SY, Kim HJ. Steroid-resistant relapsing IgG4-related pachymeningitis treated with methotrexate. JAMA neurology. 2014 Feb;71(2):222-5. PubMed PMID: 24322883.

106. Kanda H, Koya J, Uozaki H, Tateishi S, Sato K, Hagino N, et al. Membranous nephropathy with repeated flares in IgG4-related disease. Clinical kidney journal. 2013 Apr;6(2):204-7. PubMed PMID: 24976968. Pubmed Central PMCID: 4073521. 107. Sato Y, Ohshima K, Ichimura K, Sato M, Yamadori I, Tanaka T, et al. Ocular adnexal IgG4-related disease has uniform clinicopathology. Pathology international. 2008 Aug;58(8):465-70. PubMed PMID: 18705764.

108. Carruthers MN, Topazian MD, Khosroshahi A, Witzig TE, Wallace ZS, Hart PA, et al. Rituximab for IgG4-related disease: a prospective, open-label trial. Annals of the rheumatic diseases. 2015 Jun;74(6):1171-7. PubMed PMID: 25667206.

109. Mulder A, Heidt S, Vergunst M, Roelen DL, Claas FH. Proteasome inhibition profoundly affects activated human B cells. Transplantation. 2013 Jun 15;95(11):1331-7. PubMed PMID: 23624544.

110. Khan ML, Colby TV, Viggiano RW, Fonseca R. Treatment with bortezomib of a patient having hyper IgG4 disease. Clinical lymphoma, myeloma \& leukemia. 2010 Jun;10(3):217-9. PubMed PMID: 20511168. 
111. Varga C, Horvath K, Berko A, Thurmond RL, Dunford PJ, Whittle BJ.

Inhibitory effects of histamine $\mathrm{H} 4$ receptor antagonists on experimental colitis in the rat.

European journal of pharmacology. 2005 Oct 17;522(1-3):130-8. PubMed PMID: 16213481.

112. Mandlekar S, Kong AN. Mechanisms of tamoxifen-induced apoptosis.

Apoptosis : an international journal on programmed cell death. 2001 Dec;6(6):469-77.

PubMed PMID: 11595837.

113. van Bommel EF, Pelkmans LG, van Damme H, Hendriksz TR. Long-term safety and efficacy of a tamoxifen-based treatment strategy for idiopathic retroperitoneal fibrosis. European journal of internal medicine. 2013 Jul;24(5):444-50. PubMed PMID: 23246124.

114. Carruthers MN, Stone JH, Deshpande V, Khosroshahi A. Development of an IgG4-RD Responder Index. International journal of rheumatology. 2012;2012:259408. PubMed PMID: 22611406. Pubmed Central PMCID: 3348627. Epub 2012/05/23. eng. 